\author{
Jun-Gong Zhao \\ Yong-Dong Li \\ Ying-Sheng Cheng \\ Ming-Hua Li \\ Ni-Wei Chen \\ Wei-Xiong Chen \\ Ke-Zhong Shang
}

\section{Long-term safety and outcome of a temporary self-expanding metallic stent for achalasia: a prospective study with a 13-year single-center experience}

Received: 10 September 2008

Accepted: 22 December 2008

Published online: 19 March 2009

(C) The Author(s) 2009

This article is published with open access at Springerlink.com

Supported by the National Key Medical Research and Development Program of China during the 9th Five-year Plan Period (no. 96-907-03-04), Shanghai Nature Science Funds (no. 02Z1314073), Shanghai Medical Development Funds (no. 00419), the National Natural Science Foundation of China (no. 30670614).

J.-G. Zhao · Y.-D. Li ·

Y.-S. Cheng $(\triangle) \cdot$ M.-H. Li ·

K.-Z. Shang

Department of Radiology,

The Tenth Affiliated People's Hospital, Shanghai Tong Ji University,

No. 301, Middle Yan Chang Road, Shanghai, China

e-mail: chengys@sh163.net

Tel.: +86-21-64823392

Fax: +86-21-64368920

N.-W. Chen · W.-X. Chen

Department of Gastroenterology,

The Sixth Affiliated People's Hospital,

Shanghai Jiao Tong University,

Shanghai, China

\author{
Y.-S. Cheng \\ Department of Radiology, \\ The Sixth Affiliated People's Hospital, \\ Shanghai Jiao Tong University, \\ No. 600, Yi Shan Road, \\ Shanghai, China
}

\begin{abstract}
To prospectively evaluate the long-term clinical safety and efficacy of a newly designed selfexpanding metallic stent (SEMS) in the treatment of patients with achalasia. Seventy-five patients with achalasia were treated with a temporary SEMS with a $30-\mathrm{mm}$ diameter. The SEMSs were placed under fluoroscopic guidance and removed by gastroscopy 4-5 days after stent placement. Follow-up data focused on dysphagia score, technique and clinical success, clinical remissions and failures, and complications and was performed at 6 months, 1 year, and within 3 to 5 years, 5 to 8 years, 8 to 10 years, and $>10$ years postoperatively. Stent placement was technically successful in all patients.
\end{abstract}

Complications included stent migration $(n=4,5.33 \%)$, chest pain $(\mathrm{n}=28,38.7 \%)$, reflux $(\mathrm{n}=15,20 \%)$, and bleeding $(\mathrm{n}=9,12 \%)$. No perforation or 30-day mortality occurred. Clinical success was achieved in all patients 1 month after stent removal. The overall remission rates at 6 months, $1,1-3,3-5,5-8$, $8-10$, and $>10$ year follow-up periods were $100 \%, 96 \%, 93.9 \%$, $90.9 \%, 100 \%, 100 \%$, and $83.3 \%$, respectively. Stent treatment failed in six patients, and the overall remission rate in our series was $92 \%$. The median and mean primary patencies were $2.8 \pm 0.28$ years $(95 \%$ CI: $2.25-3.35)$ and $4.28 \pm 0.40$ years (95\% CI: 3.51-5.05), respectively. The use of temporary SEMSs with 30 -mm diameter proved to be a safe and effective approach for managing achalasia with a long-term satisfactory clinical remission rate.

Keywords Achalasia - Selfexpanding metallic stents $\cdot$ Dysphagia

\section{Introduction}

Pneumatic dilation (PD) is considered the first-line therapy for esophageal achalasia in many institutions [1-11] since remission can be achieved in 60 to $90 \%$ of the patients [12, 13]. However, this therapeutic strategy remains controversial since long-term remission rates after PD have been reported to drop progressively with time, from $20 \%$ to $61 \%$ at 10 years $[2,4,7,8,10,14]$, especially in young subjects [10], leading some authors to consider surgery as an alternative option.

Self-expanding metallic stents (SEMS) have been the most common form of palliative treatment of patients with malignant esophageal dysphagia and/or esophagorespiratory fistulas for the last 2 decades [15-20]. However, the use of esophageal stents in benign esophageal conditions 
has been considered to be relatively contraindicated because of concerns about an increased risk of complications, such as stent migration, reflux, perforation, bleeding, and, most importantly, new strictures caused by stentinduced tissue hyperplasia [21-27].

Recently, this traditional view has begun to change, and a number of case reports or small series of data presentations have suggested the feasibility of stent placement in the cardiac esophagus [28-33]. Since July 1994, we have used the placement of a new, specially designed self-expandable metallic stent (Youyan Yijin Advanced Materials Co., Ltd., Beijing, China) in the distal esophagus. The purpose of this study was to prospectively evaluate the long-term clinical safety and efficacy of a newly designed SEMS with a $30-\mathrm{mm}$ diameter in the treatment of patients with esophageal achalasia.

\section{Materials and methods}

\section{Study design}

This pilot study was approved by the Institutional Review Board at The Sixth Affiliated People's Hospital of Shanghai Jiao Tong University, and informed consent was obtained from each patient. From July 1994 to December 2007, we performed a prospective study of fluoroscopical placement of a SEMS in patients with primary esophageal achalasia. The inclusion criteria for stent placement were as follows: (1) documented primary esophageal achalasia; (2) recurrent dysphagia following pneumatic balloon dilation; (3) patient life expectancy of more than 6 months. The exclusion criteria were (1) a lesion longer than $6 \mathrm{~cm}$; (2) presence of dysfunction of blood coagulation, active infection, significant cardiac or pulmonary disease, malignancy, and significant psychological or psychosocial dysfunction; (3) World Health Organization (WHO) performance score $\geq 3$. The preoperative diagnosis was based on clinical presentation, barium swallow, gastroscopy, or esophageal manometry. These procedures were performed by an interventional radiologist (Y.S.C.) who had 15 years of experience in gastrointestinal interventional radiology.

Patients were evaluated before and immediately after stent placement, at 3 months, 6 months, and then every 6 months after stent removal until death. The evaluations before placement of the metal stent were performed by three radiologists participating in the study. Postoperative regular follow-up was performed by responses to a standardized questionnaire for symptoms by telephone or outpatient clinic interview, barium swallow, and, if necessary, endoscopy. Parameters evaluated during followup included: (1) WHO performance status $(0=$ normal activity, $1=$ symptoms but ambulatory, $2=$ in bed less than $50 \%$ of time, $3=$ in bed more than $50 \%$ of time, and $4=100 \%$ bedridden); (2) dysphagia score (grade 0, no dysphagia; grade 1, some solid food; grade 2, can swallow liquids only; grade 3 , difficulty with liquids and saliva; grade 4, complete dysphagia); (3) outcomes (technical and clinical success, 30-day mortality, clinical remission or failures, dysphagia score and WHO performance status, survival, and cause of death); (4) complications and recurrent dysphagia; (5) specific symptoms, such as substernal pain, heartburn, regurgitation, and fever. All evaluation items were recorded in a case record form. Prospective data collection focused on dysphagia score, technical and clinical outcome, clinical remission or failures, and specific symptoms.

\section{Stent construction and insertion procedure}

The self-expandable metallic stent was woven from a single thread of $0.16-\mathrm{mm}$ highly elastic nitinol wire with a good histocompatibility and memory. On the one hand, the stent could expand to its expected and maximal diameter at body temperature; on the other hand, the stent could shrink and become soft at cold temperatures. The stent had a tubular configuration as shown in Fig. 1. The body of the stent covered with polyethylene was $30 \mathrm{~mm}$ in diameter and $60-80 \mathrm{~mm}$ in length when fully expanded. Three radiopaque markers made of gold wire attached at both ends and in the middle of the body part facilitated precise placement of the stent. The stents were constructed by a manufacturer (Youyan Yijin) according to our specifications. For implantation under fluoroscopic guidance, the stent was mounted in a compressed state on the guiding tube by the introducer sheath $24 \mathrm{Fr}(8 \mathrm{~mm})$ in diameter.

The self-expandable metallic stent was developed by both our institute and the Youyan Yijin Advanced Materials Cooperation (Youyan Yijin). It was specifically designed for placement of the stent in the esophageal cardia. Topical anesthesia of the pharynx using an aerosol spray was routinely performed before the procedure, and sedative drugs were not used. Details of the stent placement

Fig. 1 Photograph of a partially covered self-expandable metallic stent $(60 \mathrm{~mm} \times 30 \mathrm{~mm})$

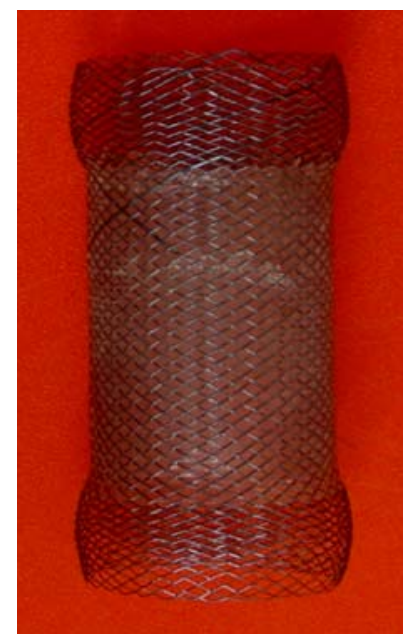


techniques are provided elsewhere [28, 29]. In brief, prior to the procedure, a water-soluble contrast swallow (Ultravist 300; Schering, GuangZhou, China) was used to indicate the proximal and distal borders of the esophageal achalasia. After topical anesthesia (lidocaine 2\%), a 0.035-inch guide wire (Radiofocus M; Terumo, Tokyo, Japan) with a straight 5-Fr catheter (Torcon NB; Cook, Bloomington, IN) was advanced perorally until the tip reached the gastric body and then exchanged for a stiffer one (0.035-inch Amplatz super-stiff). A 24-Fr delivery system (Youyan Yijin) was inserted over the guide wire until the proximal and distal edges of the stent bridged the esophageal achalasia under fluoroscopic control, and the stent was then deployed by pulling back the introducer sheath. Correct placement of the stent and satisfactory achalasia coverage were confirmed by contrast-enhanced fluoroscopy with peroral administration of water-soluble contrast (Ultravist) after deploying the stent. Patients ate semisolid food on the day after stent placement and were given prophylactic $\mathrm{H}_{2}$ receptor blockade to prevent reflux esophagitis.

Retrieval of the stent was performed with the help of a gastroscopy 3-7 days after stent placement. First, 500 $1,000 \mathrm{ml}$ of ice-cold water was injected via the bioptic hole to retract the stent, and then the stent was grasped by the retrieval lasso or the proximal stent wire and gently pulled out. Usually less than $10 \mathrm{~min}$ was required for this procedure. Gastroscopy and esophageal radiography were performed immediately after removal of the stent to rule out possible complications, such as bleeding, perforation, etc.

\section{Postoperative outcome evaluation}

Technical success was defined as successful insertion of the stent into the esophageal achalasia without any major complications, such as esophageal rupture or massive bleeding. Clinical success was defined as the symptomatic improvement in dysphagia and good esophageal emptying on esophagography 1 month after removal of the stent. Primary patency was defined as the time interval from stent remove to clinical failure without subsequent stent placement or balloon dilation.

Complications, including esophageal perforation, chest pain, and reflux, were evaluated. Esophageal perforation was defined as contrast leakage from the esophageal lumen on immediate esophagography or pneumomediastinum or pneumoperitoneum on immediate chest radiograph. Severe pain was defined as pain that developed after stent placement requiring narcotic analgesics. Gasotroesophageal reflux was defined as contrast reflux through the gasotroesophageal junction, as confirmed by follow-up esophagography.

All patients were followed up as outpatients for a mean of 4.01 \pm 3.18 years (range: 0.5-11.8 years). Outcome assessment was performed at 6 months, 1 year, and within 3 to 5 years, 5 to 8 years, 8 to 10 years, and $>10$ years postoperatively. The clinical follow-up evaluation was focused on dysphagia, regurgitation, heartburn, and substernal pain. The incidence of each symptom was graded according to the proposal by Johnson and De Meester [34] as follows: grade 0, absence of the symptom; grade 1, occasional episodes of the symptom reported to occur less than once weekly; grade 2, frequent episodes of the symptom reported to occur more than once weekly; grade 3 , persisting daily symptoms. To estimate the effectiveness of treatment, the following grading system was used: A score of 0 to 2 was considered excellent, 3 to 5 was considered good, 6 to 8 was considered fair, and 9 to 12 was considered poor. Excellent/good results were considered as clinical remission, whereas fair/poor results were clinical failures. Patients with poor results were candidates for subsequent balloon dilation or stent placement.

\section{Statistical analysis}

All the data were expressed as the mean $\pm \mathrm{SD}$. Comparisons of pre- and postprocedure dysphagia score between the two groups were performed by applying the Mann-Whitney test. The curve of primary patency was calculated according to the Kaplan-Meier method. Statistical analyses were performed using SPSS statistical software (version 13.0 for Windows, SPSS Inc., Chicago, IL). A $p$ value $<0.05$ was considered significant.

\section{Results}

\section{Demographics}

The characteristics of the patient population in this study are summarized in Table 1. A total of 75 patients who underwent stent placement for achalasia during the 13-year study period were enrolled in the analysis. These included 36 men and 39 women with a mean age of $36.36 \pm$ 12.33 years (range: $12-72$ years). The mean time interval between a significant dysphagia confirmation and stent placement was $5.23 \pm 3.49$ years (ranging from 1.114.6 years). Current symptoms were dysphagia $(n=75$, $100 \%)$, chest pain $(n=47,71 \%)$, regurgitation $(n=37$, $23 \%)$, and heartburn $(n=28,23 \%)$, with a mean weight loss of $3.42 \pm 3.07 \mathrm{~kg}$ (range: $0.3-12.6 \mathrm{~kg}$ ). The mean dysphagia score before stent placement was $2.8 \pm 0.52$. The mean diameter of the narrowest region of the cardia was $5.98 \pm$ $2.18 \mathrm{~mm}$ with a mean length of $19.24 \pm 6.45 \mathrm{~mm}$.

Technical and initial clinical outcome

Fluoroscopic stent placement in the distal esophagus was technically successful in all patients without procedurerelated complications. Initially, all patients required the 
placement of only one stent to cover the length of the esophageal achalagia. Complete expansion of the placed stent occurred within $24 \mathrm{~h}$ after stent placement. No patient underwent balloon dilatation, either before or after stent placement. The mean time of the procedure was $19 \pm 6 \mathrm{~min}$ (range, 10-30 min).

Stent migration occurred in four $(5.33 \%)$ patients, and all of them needed a second stent placement 2-4 days after stent placement. Twenty-eight (38.7\%) patients complained of chest pain within 5 days after stent placement, in which two required analgesics for severe pain. Reflux and bleeding (after stent removal) were observed in 15 $(20 \%)$ and $9(12 \%)$ patient, respectively, both of which were alleviated or disappeared spontaneously following stent removal without additional treatment. No perforation or food impaction occurred in our series after stent placement, and there was no 30-day mortality.

The clinical symptoms of dysphagia resolved in all patients, and all patients were able to swallow satisfactorily within $24 \mathrm{~h}$ after successful stent placement. The average time from SEMS placement to stent removal was 4 to 5 days. Clinical success was achieved in all patients with patency of the distal esophagus 1 month after stent removal, and the dysphagia score significantly improved for all patients, with a median score of $2.8 \pm$ 0.52 before stent placement to a median score of $0.19 \pm$ $0.39(P<0.001)$.

\section{Long-term follow-up and final outcome}

The long-term follow-up and clinical outcome following stent treatment at different follow-up time points are shown in Table 1. The mean time from stent removal to last follow-up assessment was $4.01 \pm 3.18$ years (range: 0.5-11.8 years). All patients were followed up and assessed at 6 months and 1 year, 66 were assessed for 1-3 years, 33 were assessed for 3-5 years, 24 were assessed for 5-8 years, 13 were assessed for 810 years, and 6 were assessed for more than 10 years, prospectively.
Follow-up evaluation at 3 months and 1 year postoperatively

At 6 months postoperatively, the mean dysphagia score of $0.23 \pm 0.38$ decreased significantly compared with the mean preoperative value $2.8 \pm 0.52(P<0.001)$. The mean dysphagia score at the 1-year postoperative follow-up evaluation was $0.25 \pm 0.45$ with an overall excellent and good successe rate of $96 \%$. None of the patients exhibited dysphagia relapse during a 6-month follow-up, and 3 patients out of 75 exhibited dysphagia relapse during a 612-month follow-up.

Long-term follow-up evaluation

The overall mean symptom score at the 1-, 3-, 5-, $8^{-}$, and $>10$-year follow-up remained significantly lower than the preoperative values. The cumulative clinical remission rates at $1-3,3-5,5-8,8-10$, and $>10$ years after stent removal for achalasia were $93.9 \%, 90.9 \%, 100 \%, 100 \%$, and $83.3 \%$, respectively (Figs. 2 and 3).

Within the 13-year follow-up period, stent treatment was considered to have failed in six patients after a median follow-up period of $3.18 \pm 3.83$ years (range 0.610.4 years), and the overall cumulative success rate in our series was $92 \%$. Four patients continued to be followed up due to mild recurrent dysphagia, and the remaining two decided to undergo Heller myotomy and were excluded from this study. None of the patients died at the end of this report.

Cessation of primary patency occurred in six patients as a result of recurrence. The median and mean primary patency was $2.8 \pm 0.28$ years (95\% CI: $2.25-3.35)$ and $4.28 \pm 0.40$ years $(95 \% \mathrm{CI}: 3.51-5.05)$, respectively.

\section{Discussion}

Treatment of achalasia with the use of SEMS, originally used as a last resort in patients who had failed medical

Table 1 The long-term follow-up and clinical outcome following stent treatment at different follow-up time points

\begin{tabular}{|c|c|c|c|c|c|c|c|}
\hline \multirow[t]{2}{*}{ Follow-up } & \multirow[t]{2}{*}{ No. of patients } & \multicolumn{3}{|c|}{ Clinical remission } & \multicolumn{3}{|c|}{ Clinical failure } \\
\hline & & Excellent & Good & $\%$ & Fair & Poor & $\%$ \\
\hline 6 months & 75 & 72 & 3 & 100 & & & \\
\hline 1 year & 75 & 70 & 2 & 96 & 3 & & 4 \\
\hline $1-3$ years & 66 & 36 & 26 & 93.9 & 4 & & 6.1 \\
\hline $3-5$ years & 33 & 19 & 11 & 90.9 & 2 & 1 & 9.1 \\
\hline $5-8$ years & 24 & 2 & 22 & 100 & & & \\
\hline $8-10$ years & 13 & 2 & 11 & 100 & & & \\
\hline$>10$ years & 6 & & 5 & 83.3 & 1 & & 16.7 \\
\hline
\end{tabular}


Fig. 2 Erect fluoroscopic images in a 42-year-old woman with primary achalasia. (a) Antero-posterior esophagogram before stent placement shows a smooth tapered beak-like appearance (arrow) at the level of the gastroesophageal junction with significant esophageal barium retention. (b) A $30-\mathrm{mm}$ diameter stent was placed at the gastroesophageal junction with successful dilation of the lower esophageal segment, and an antero-posterior esophagogram immediately after stent placement confirms complete esophageal emptying with symptom relief. (c) Left anterior oblique esophagogram after removal of the stent demonstrates significant improved contrast passage through the widened lumen (arrow) at the level of the gastroesophageal junction with complete improvement of her symptoms. (d) Right anterior oblique esophagogram 5 years after stent removal displays improved contrast passage through the gastroesophageal junction with relief of the symptoms. (e) Lateral esophagogram 10 years after stent removal shows improvement of esophageal barium emptying with no residual symptoms
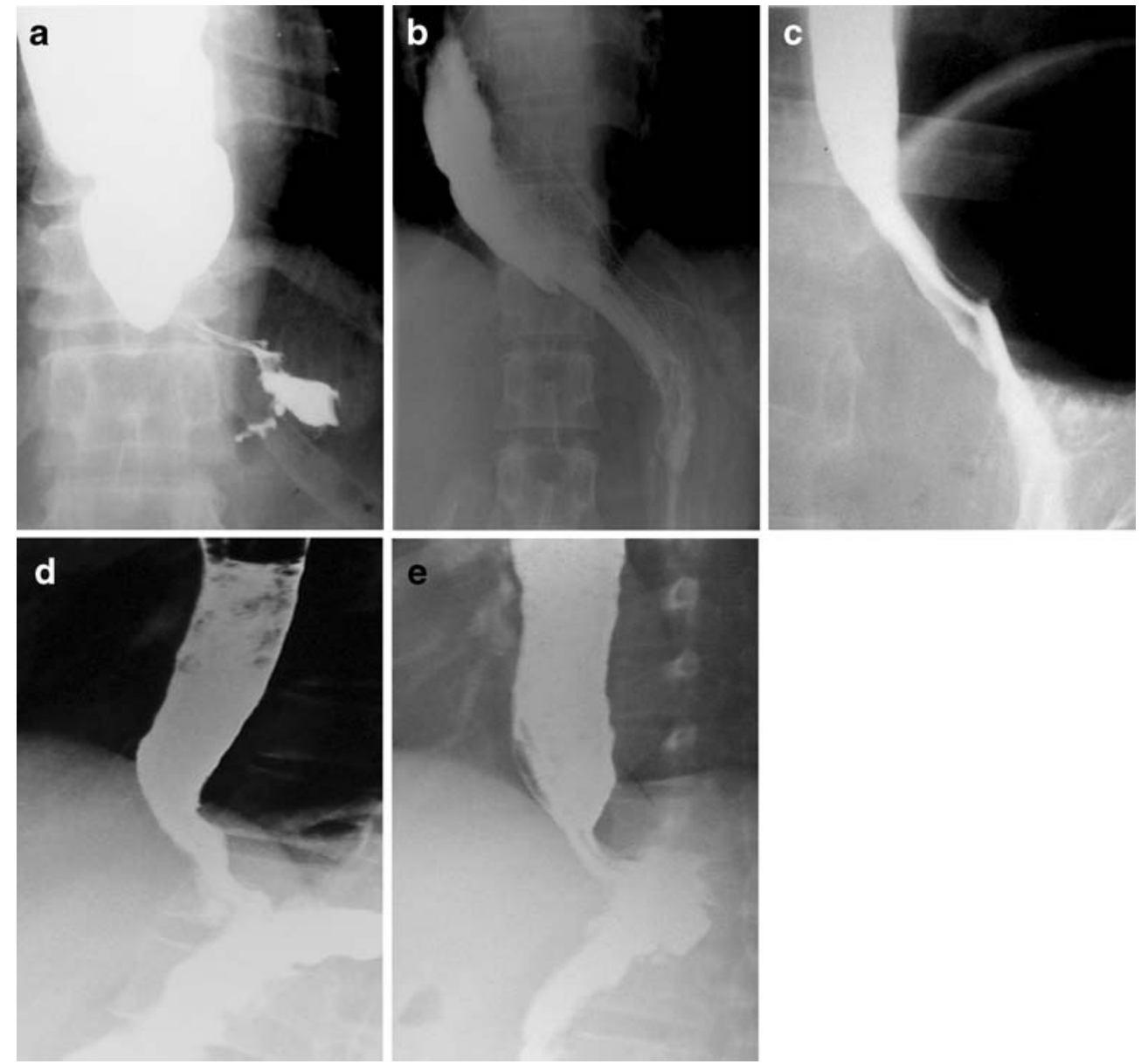

therapy or pneumatic dilation, or who were poor surgical candidates, was first described by De Palma in 1998 with encouraging results [33]. To date, only a few reports in the English literature describe treating achalasia with the use of SEMS [23, 27, 32, 33]. Although the management of benign esophageal strictures with stent placement is becoming better established, some authors do not recommend using EMS in achalasia because of poor results and complications [23, 27, 32]. However, we believe that temporary SEMSs are helpful in the treatment of achalasia [28-31]. These long-term results suggest that treatment of achalasia with the use of SEMS is safe and feasible.

The new large-sized, temporary SEMS has two unique advantages over the conventional, permanent, small-sized stent and pneumatic dilatation: (1) it provides long-term good clinical symptomatic remission of dysphagia with one session of stent placement; (2) it maximally decreases the risk of complications, such as stent migration, perforation, and new strictures caused by stent-induced tissue hyperplasia.

In this uncontrolled prospective study of 75 patients with achalasia, the newly designed SEMS placement was technically successful in all of the patients, with a post- procedural clinical success rate of $100 \%$. There was no procedure-related mortality and perforation in this study, and all complications were temporary and could be managed without surgical intervention. The SEMS placement led to a $96 \%$ clinical remission rate at 1-year followup. Over the $>5$-year and $>-10$-year follow-up periods, the clinical remission remained high and effective in $100 \%$ and $83.3 \%$ of patients, respectively. Our data showed a longer term remission rate than did the results of other published studies with repeated pneumatic dilatations [1-14]. The long-term follow-up results showed that this new stent design provided excellent/good symptomatic relief of achalasia in most of the patients (Fig. 2). To date, there have been no randomized and prospective clinical trials examining the utility of SEMS placement in the treatment of patients with achalasia. This study was the largest series of SEMS placements reported for managing patients with achalasia; it addressed the role of SEMS in patients with achalasia and demonstrated the long-term safety and effectiveness of temporary SEMS placement as an alternative approach for achalasia. The results were also much better than the previous reports of treating achalasia with the use of SEMS $[23,27,32,33]$. The difference lies 
Fig. 3 Curves of clinical remission rate changing over time during 13-year follow-up

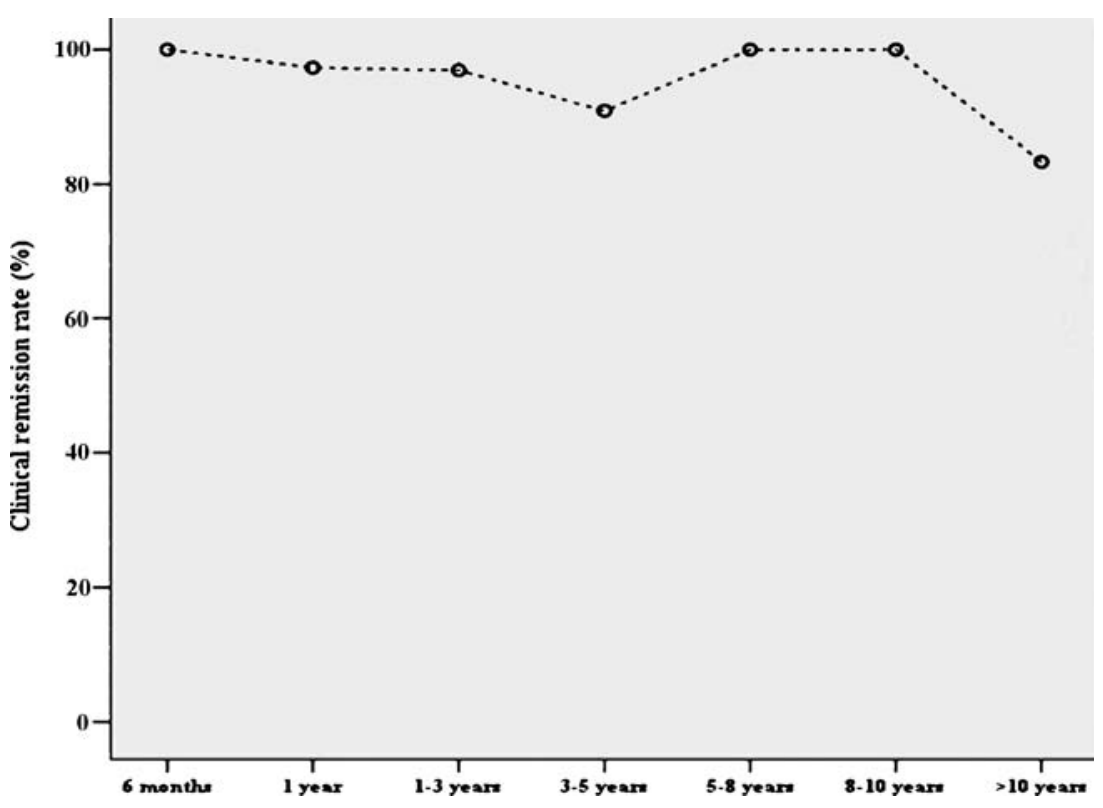

in the fact that the stent we used was a temporary SEMS with a $30-\mathrm{mm}$ diameter and not the commonly used permanent, small-sized stent.

Stent migration was the the most frequent complication for stents placed for benign strictures, ranging from $18.7 \%$ $81.8 \%$ [23-25, 35]. Although different types of esophageal SEMS have been used, these stents were of comparatively small diameter and limited radial force, attributes that may have contributed to the more frequent occurrence of migration. In this study, the lower migration rate $(5.3 \%$, 4/75) may seem to contribute to the effectiveness of largesized temporary SMES. The suggested mechanism for stent migration in our series was thought to be prevented by the great radial expansile force and friction between the uncovered nitinol wire tube and the esophageal wall. We were able to demonstrate that the stent was resistant to migration in 71 of $75(94.7 \%)$ patients, which indicated that the stent design specialized for cardiac application has exerted great influence on preventing stent migration and might have helped to minimize the likelihood of migration. However, the large-sized SEMS with great radial force may result in another serious complication-perforation.

Perforation is a serious complication found in $1 \%$ and $5 \%$ of patients with pneumatic dilation in a large series [2] and a systematic review [36], and the incidence will be high with the increase of the balloon diameter $(>30 \mathrm{~mm})$ [1]. In this study, we observed no incidents of esophageal perforation during stent placement. The main reason may be attributed to the characteristic of the SEMS. The stent expanded to its full size within $24 \mathrm{~h}$ after placement, and the radial expansile force was generated spontaneously, slowly, and evenly during stent expansion. Thus, the tearing of the cardiac musculature by the stent was slow and gentle, and not like the pneumatic dilation, which can cause acute and sudden tears. The spontaneous, slowly and evenly generated radial expansile force ensured the safety of stent placement and maximally decreased the risk of perforation. As for new strictures induced by the long-term stent placement as mentioned above [23, 27, 32, 33], there was little likelihood of tissue hyperplasia in our series due to short-term stent placement.

Although the incidence of stent migration, perforation, and new strictures was decreased with the use of the largesized temporary stent, the concomitant complications following stent placement, such as chest pain $(38.7 \%$, $28 / 75)$, gastro-esophageal reflux $(20 \%, 15 / 75)$, and bleeding $(12 \%, 9 / 75)$, were a little higher than those following pneumatic dilatation [2-11,36], perhaps because of the radial force and expansion of the stent. These complications were temporary and were alleviated or disappeared spontaneously after removal of the stent, and without additional treatment in most of the cases. As for the possible mechanism for temporary stent placement, we considered that it mainly was attributed to slow tearing of the cardia muscularis with stent expansion. Generally, at body temperature, the stent would gradually expand to the expected diameter within $24 \mathrm{~h}$, and the cardia muscularis was torn slowly and regularly with relatively few scars during stent expansion. Therefore, the incidence of restenosis was very low when it was repaired [31].

This study, however, had a few limitations. This was a single-center study with no control studies. Therefore, future randomized trials comparing our stent and pneumatic dilatation are needed to compare the efficacy, risk of complications, and recurrent dysphagia, with particular attention given to perforation, reflux, stent migration, and long-term clinical efficacy. We only used subjective criteria to assess the long-term clinical remission or failure after stent treatment in this study; some better scientific assessment, such as esophageal manometry, $\mathrm{PH}$ value of the lower esophageal 
sphincter, or timed barium esophagram, should be added to more precisely evaluate the long-term clinical outcomes.

In conclusion, despite some temporary complications concomitant with stent placement, our long-term results demonstrate that the newly designed temporary SEMS with a 30-mm diameter was a safe and effective device for treating clinical symptomatic remission of esophageal achalasia. The large-sized temporary SEMS may be an important tool for reducing the risk of complications, such as stent migration, perforation, and new strictures, and it ensured a long-term duration of efficacy, which may justify the use of self-expanding metal stents in benign esophageal achalasia and serve as an alternative or complementary method to pneumatic dilatation.

Open Access This article is distributed under the terms of the Creative Commons Attribution Noncommercial License which permits any noncommercial use, distribution, and reproduction in any medium, provided the original author(s) and source are credited.

\section{References}

1. Yi A, Shin JH, Song HY, Jung HY, Lee GH, Yoon CJ, Choi E, Kim KR, Kim JH (2008) Esophageal achalasia: comparison of fluoroscopically-guided double vs. endoscopically-guided single balloon dilation. Abdom Imaging 33:177-182

2. Lopushinsky SR, Urbach DR (2006) Pneumatic dilatation and surgical myotomy for achalasia. JAMA 296:2227-2233

3. Zerbib F, Thétiot V, Richy F, Benajah DA, Message L, Lamouliatte H (2006) Repeated pneumatic dilations as longterm maintenance therapy for esophageal achalasia. Am J Gastroenterol 101:692-697

4. Vela MF, Richter JE, Khandwala F, Blackstone EH, Wachsberger D, Baker ME, Rice TW (2006) The long-term efficacy of pneumatic dilatation and Heller myotomy for the treatment of achalasia. Clin Gastroenterol Hepatol 4:580-587

5. Boztas G, Mungan Z, Ozdil S, Akyüz F, Karaca C, Demir K, Kaymakoglu S, Besisik F, Cakaloglu Y, Okten A (2005) Pneumatic balloon dilatation in primary achalasia: the long-term follow-up results. Hepatogastroenterology 52:475480

6. Khan AA, Shah SW, Alam A, Butt AK, Shafqat F (2005) Sixteen years follow up of achalasia: a prospective study of graded dilatation using Rigiflex balloon. Dis Esophagus 18:41-45

7. Katsinelos P, Kountouras J, Paroutoglou G, Beltsis A, Zavos C, Papaziogas B, Mimidis K (2005) Long-term results of pneumatic dilation for achalasia: a 15 years' experience. World J Gastroenterol 11:5701-5705

8. Karamanolis G, Sgouros S, Karatzias G, Papadopoulou E, Vasiliadis K, Stefanidis G, Mantides A (2005) Longterm outcome of pneumatic dilation in the treatment of achalasia. Am J Gastroenterol 100:270-274
9. Dobrucali A, Erzin Y, Tuncer M, Dirican A (2004) Long-term results of graded pneumatic dilatation under endoscopic guidance in patients with primary esophageal achalasia. World J Gastroenterol 10:3322-3327

10. Eckardt VF, Gockel I, Bernhard G (2004) Pneumatic dilation for achalasia: late results of a prospective follow up investigation. Gut 53:629-633

11. Sabharwal T, Cowling M, Dussek J, Owen W, Adam A (2002) Balloon dilation for achalasia of the cardia: experience in 76 patients. Radiology 224:719-724

12. Vaezi MF, Richter JE (1999) Diagnosis and management of achalasia. American College of Gastroenterology Practice Parameter Committee. Am J Gastroenterol 94:3406-3412

13. Vaezi MF, Richter JE (1998) Current therapies for achalasia: Comparison and efficacy. J Clin Gastroenterol 27:21-35

14. Ghoshal UC, Kumar S, Saraswat VA, Aggarwal R, Misra A, Choudhuri G (2004) Long-term follow-up after pneumatic dilation for achalasia cardia: factors associated with treatment failure and recurrence. Am J Gastroenterol 99:2304-2310

15. Guo JH, Teng GJ, Zhu GY, He SC, Fang W, Deng G, Li GZ (2008) Selfexpandable esophageal stent loaded with 125I seeds: initial experience in patients with advanced esophageal cancer. Radiology 247:574-581

16. Bartelsman JF, Bruno MJ, Jensema AJ, Haringsma J, Reeders JW, Tytgat GN (2000) Palliation of patients with esophagogastric neoplasms by insertion of a covered expandable modified Gianturco-Z endoprosthesis: experiences in 153 patients. Gastrointest Endosc 51:134-138

17. Song HY, Do YS, Han YM, Sung KB, Choi EK, Sohn KH, Kim HR, Kim SH, Min YI (1994) Covered, expandable esophageal metallic stent tubes: experiences in 119 patients. Radiology 193:689-695
18. Knyrim K, Wagner HJ, Bethge N, Keymling M, Vakil N (1993) A controlled trial of an expansile metal stent for palliation of esophageal obstruction due to inoperable cancer. N Engl J Med 329:1302-1307

19. Wu WC, Katon RM, Saxon RR, Barton RE, Uchida BT, Keller FS, Rosch J (1994) Silicone-covered self-expanding metallic stents for the palliation of malignant esophageal obstruction and esophagorespiratory fistulas: experience in 32 patients and a review of the literature. Gastrointest Endosc 40:2233

20. Shin JH, Song HY, Ko GY, Lim JO, Yoon HK, Sung KB (2004) Esophagorespiratory fistula: long-term results of palliative treatment with covered expandable metallic stents in 61 patients. Radiology 232:252-259

21. Repici A, Conio M, De Angelis C, Battaglia E, Musso A, Pellicano R, Goss M, Venezia G, Rizzetto M, Saracco G (2004) Temporary placement of an expandable polyester silicone-covered stent for treatment of refractory benign esophageal strictures. Gastrointest Endosc 60:513-519

22. Song HY, Jung HY, Park SI, Kim SB, Lee DH, Kang SG, Il Min Y (2000) Covered retrievable expandable nitinol stents in patients with benign esophageal strictures: initial experience. Radiology 217:551-557

23. De Palma GD, lovino P, Masone S, Persico M, Persico G (2003) Selfexpanding metal stents for endoscopic treatment of esophageal achalasia unresponsive to conventional treatments. Long-term results in eight patients. Endoscopy 33:1027-1030

24. Holm AN, de la Mora Levy JG, Gostout CJ, Topazian MD, Baron TH (2008) Self-expanding plastic stents in treatment of benign esophageal conditions. Gastrointest Endosc 67:20-25 
25. Radecke K, Gerken G, Treichel U (2005) Impact of a self-expanding, plastic esophageal stent on various esophageal stenoses, fistulas, and leakages: a single-center experience in 39 patients. Gastrointest Endosc 61:812-818

26. Sheikh RA, Trudeau WL (1998) Expandable metallic stent placement in patients with benign esophageal strictures: results of long-term follow-up. Gastrointest Endosc 48:227-229

27. Lee JG, Hsu R, Leung JW (2000) Are self-expanding metal mesh stents useful in the treatment of benign esophageal stenoses and fistulas? An experience of four cases. Am J Gastroenterol 95:1920-1925
28. Cheng YS, Li MH, Chen WX, Zhuang QX, Chen NW, Shang KZ (2003) Follow-up evaluation for benign stricture of upper gastrointestinal tract with stent insertion. World J Gastroenterol 9:2609-2611

29. Cheng YS, Li MH, Chen WX, Chen NW, Zhuang QX, Shang KZ (2003) Temporary partially-covered metal stent insertion in benign esophageal stricture. World J Gastroenterol 9:2359-2361

30. Cheng YS, Li MH, Chen WX, Chen NW, Zhuang QX, Shang KZ (2004) Complications of stent placement for benign stricture of gastrointestinal tract. World J Gastroenterol 10:284-286

31. Cheng YS, Li MH, Chen WX, Chen NW, Zhuang QX, Shang KZ (2003) Selection and evaluation of three interventional procedures for achalasia based on long-term follow-up. World J Gastroenterol 9:2370-2373

32. Mukherjee S, Kaplan DS, Parasher G, Sipple MS (2000) Expandable metal stents in achalasia-is there a role? Am J Gastroenterol 95:2185-2188
33. De Palma GD, Catanzano C (1998) Removable self-expanding metal stents: a pilot study for treatment of achalasia of the esophagus. Endoscopy 30:S95-S96

34. Tsiaoussis $\mathrm{J}$, Athanasakis E, Pechlivanides G, Tzortzinis A, Gouvas N, Mantides A, Xynos E (2007) Long-term functional results after laparoscopic surgery for esophageal achalasia. Am J Surg 193:26-31

35. Costamagna G, Shah SK, Tringali A, Mutignani M, Perri V, Riccioni ME (2003) Prospective evaluation of a new self-expanding plastic stent for inoperable esophageal strictures. Surg Endosc 17:891-895

36. Lake JM, Wong RK (2006) Review article: the management of achalasia - a comparison of different treatment modalities. Aliment Pharmacol Ther 24:909-918 